\title{
Efficacy of dual antiplatelet therapy as premedication before diagnostic cerebral digital subtraction angiography
}

\author{
Yoon-Hee Choo, Young-Jin Jung, Chul-Hoon Chang, Jong-Hoon Kim \\ Department of Neurosurgery, Yeungnam University College of Medicine, Daegu, Republic of Korea \\ Objective : Several studies have reported that periprocedural dual anti- \\ platelet therapy lowers the incidence of thromboembolic complications \\ (TEC) associated with coiling of unruptured aneurysms. We hypothesized \\ $J$ Cerebrovasc Endovasc Neurosurg. \\ 2019 September;21(3):131-137 \\ Received : 13 July 2019 \\ Revised : 18 September 2019
} that preprocedural administration of dual antiplatelet agents (aspirin and cilostazol) for 7days may reduce the risk of complications associated with diagnostic cerebral digital subtraction angiography (DSA).

Methods : We retrospectively reviewed the records of patients who underwent diagnostic cerebral DSA between September 2015 and April 2018. Of the 419 patients included $(149$ men, 270 women, mean age 58.5 years), 221 (72 men, 149 women, mean age 57.8 years) who underwent cerebral DSA between September 2015 and June 2016 were not premedicated with antiplatelet therapy. The remaining 198 (77 men, 121 women, mean age 59.4 years) who underwent cerebral DSA between July 2016 and April 2018 were premedicated with dual antiplatelet therapy (aspirin and cilostazol). We defined ischemic stroke as a cerebral DSA-induced complication identified on magnetic resonance imaging (MRI) among patients with neurological symptoms.

Results : Of the 221 patients who did not receive antiplatelet therapy, 210 (95.0\%) showed no neurological symptoms; however, 11 (5.0\%) developed neurological symptoms with MRI-proven ischemic stroke, which represents a TEC. Of the 198 patients who received dual antiplatelet therapy, 196 patients $(99.0 \%)$ showed no evidence of TEC. The remaining $2(1.0 \%)$ developed diplopia and motor weakness each, and MRI confirmed acute ischemic stroke $(p=0.019)$.

Conclusions : The use of dual antiplatelet agents (aspirin and cilostazol) for 7 days before DSA may reduce the risk of cerebral DSA-induced TEC.

Keywords digital subtraction angiography, antiplatelet therapy, premed-

This is an Open Access article distributed under the terms of the Creative Commons Attribution NonCommercial License (http://creativecommons.org/licenses/by-nc/3.0) which permits unrestricted noncommercial use, distribution, and reproduction in any ication, thromboembolism

Correspondence to Jong-Hoon Kim Department of Neurosurgery, Yeungnam University College of Medicine, 170 Hyeonchung-ro, Nam-gu, Daegu, Republic of Korea

Tel : +82-53-620-3790, 3792

Fax : +82-53-620-3770

E-mail : kjhns@yu.ac.kr

ORCID : http://orcid.org/0000-0001-9492-6901

\section{INTRODUCTION}

Following the availability of novel technology, cerebral digital subtraction angiography (DSA) is commonly used clinically to diagnose cerebrovascular abnormalities ${ }^{8}$. Cerebral DSA is a safe procedure; how- ever, complications may occur in rare cases $^{688}$. Considering the widespread use of cerebral DSA as a general diagnostic modality for cerebrovascular disease, it is important to reduce the complications related to this technique.

Among the various complications of cerebral DSA 
including nausea, vomiting, transient hypotension, anaphylaxis, and groin hematoma)23), we focused on neurological complications secondary to thromboembolism. Thromboembolism is the most significant complication of cerebral DSA ${ }^{14)}$, which occurs secondary to thrombus formation within catheters, within pre-existing friable intravascular thrombotic plaques, or device-induced microdissections ${ }^{11)}$.

Antiplatelet and anticoagulant therapy effectively reduces the risk of thromboembolism ${ }^{13) 18)}$. Several studies have reported that periprocedural antiplatelet therapy effectively lowers the incidence of thromboembolic complications (TEC) that may occur with coiling of unruptured aneurysms ${ }^{15-17) 24)}$. However, to the best of our knowledge, no studies have been performed for diagnostic cerebral DSA. We hypothesized that preprocedural administration of dual antiplatelet agents (aspirin and cilostazol) for 7 days may reduce the risk of complications associated with diagnostic cerebral DSA.

\section{MATERIALS AND METHODS}

\section{Patients}

We retrospectively reviewed the records of 419 patients who underwent diagnostic cerebral DSA between September 2015 and April 2018 (Table 1). Among these 419 patients, 221 patients who underwent diagnostic cerebral DSA from September 2015 to June 2016 did not received dual antiplatelet therapy as premedication. The remaining 198 patients who underwent diagnostic cerebral DSA between July 2016 and April 2018 received dual antiplatelet therapy as premedication. We changed the strategy because the incidence of TEC was higher than we thought when no premedication was given. Patient consent was waived for this study owing to the retrospective study design. Inclusion criteria for this study were non-ruptured aneurysms, arteriovenous malformations, and arteriovenous fistulas, stenosis or occlusion of cerebral artery, as well as postoperative evaluation 1-2 years after coiling or clipping (Table 2). Patients with DSA performed for subarachnoid hemorrhage
(SAH), patients with SAH presenting for a week follow-up angiography, patients with an acute or subacute stroke, patients with symptoms of a transient ischemic attack within 4 weeks of the scheduled cerebral DSA, patients with evidence of intracerebral hemorrhage, those with a history of neurosurgical or interventional procedures 4 weeks prior to the study, and those with congestive heart disease or cardiac arrhythmia were excluded. We defined cerebral DSA-related TEC as the occurrence of acute ischemic stroke that was confirmed on MRI within 48 hours of testing among patients presenting with neurological symptoms.

\section{Procedures}

Cerebral DSA was performed via the transfemoral arterial approach using a dedicated biplane neuroangiography unit (RF-1000-125, Artis Zee biplane, Siemens Healthineer, Berlin, Germany) with the help of 1 type of guidewire (Terumo ${ }^{\circledR}, 0.035$ inch, Tokyo, Japan) and 3 types of catheters-Taper (Cook, Bloomington, IN, USA), Imager (Boston Scientific, Marlborough, MA, USA), Simmons I (AngioDynamics, Queensbury, NY, USA). A non-ionic contrast medium (lomeron 300 [iomeprol $612.4 \mathrm{mg} / \mathrm{mL}$ ], Bracco S.p.A., Milan, Italy) was used for all procedures with automatic machine injection of the contrast medium fol-

Table 1. Characteristics of the study population

\begin{tabular}{lccc}
\hline & $\begin{array}{c}\text { Without } \\
\text { premedication }\end{array}$ & $\begin{array}{c}\text { With } \\
\text { Premedication }\end{array}$ & Total \\
\hline Number of patients & 221 & 198 & 419 \\
Male & 72 & 77 & 149 \\
Female & 149 & 121 & 270 \\
Mean age (years) & $57.8(21-80)$ & $59.4(19-80)$ & 58.6 (19-80) \\
\hline
\end{tabular}

Table 2. Inclusion criteria for the study

\begin{tabular}{lr}
\hline Cases in premedication & Number \\
\hline Unruptured aneurysm & $338(80.67 \%)$ \\
Intervention evaluation & $51(12.17 \%)$ \\
Arteriovenous malformation & $9(2.15 \%)$ \\
Carotid carvernous fistula & $5(1.19 \%)$ \\
Moyamoya & $2(0.48 \%)$ \\
Stenosis/occlusion/dissection & $13(3.10 \%)$ \\
Atherosclerosis & $1(0.24 \%)$ \\
\hline Total & 419 \\
\hline
\end{tabular}


lowed by a saline flush after each injection. The FemoSeal $^{\circledR}$, vascular closure device, was used for hemostasis at the site of vascular access. All procedures in this series were performed by a single neurovascular surgeon (the author of this study).

\section{Drug Protocols}

Patients who underwent DSA between July 2016 and April 2018 received aspirin and cilostazol (both $100 \mathrm{mg} /$ day) for 7 days. All antiplatelet therapy was discontinued post-procedure in premedicated patients who underwent cerebral DSA but did not develop TEC.

\section{Statistical Analysis}

Comparison between two groups was performed us-

Table 3-1. Correlation between risk factors and the incidence of thromboembolic complications secondary to cerebral digital subtraction angiography in non-pretreated dual antiplatelet therapy as premedication

\begin{tabular}{|c|c|c|c|c|}
\hline Risk factor & complication & NO & YES & p-value \\
\hline Hypertension & $\begin{array}{l}\text { No } \\
\text { Yes }\end{array}$ & $\begin{array}{l}110 \\
100\end{array}$ & $\begin{array}{l}7 \\
4\end{array}$ & 0.466 \\
\hline Diabetes mellitus & $\begin{array}{l}\text { No } \\
\text { Yes }\end{array}$ & $\begin{array}{c}180 \\
30 \\
\end{array}$ & $\begin{array}{l}9 \\
2 \\
\end{array}$ & 0.720 \\
\hline Hyperlipidemia & $\begin{array}{l}\text { No } \\
\text { Yes }\end{array}$ & $\begin{array}{c}191 \\
19 \\
\end{array}$ & $\begin{array}{c}10 \\
1 \\
\end{array}$ & 0.996 \\
\hline Stroke history & $\begin{array}{l}\text { No } \\
\text { Yes }\end{array}$ & $\begin{array}{c}171 \\
39\end{array}$ & $\begin{array}{c}10 \\
1\end{array}$ & 0.426 \\
\hline heart disease & $\begin{array}{l}\text { No } \\
\text { Yes }\end{array}$ & $\begin{array}{c}195 \\
15\end{array}$ & $\begin{array}{c}11 \\
0\end{array}$ & 0.359 \\
\hline Smoking & $\begin{array}{l}\text { No } \\
\text { Yes }\end{array}$ & $\begin{array}{l}185 \\
25\end{array}$ & $\begin{array}{l}9 \\
2 \\
\end{array}$ & 0.535 \\
\hline Chronic kidney disease & $\begin{array}{l}\text { No } \\
\text { Yes }\end{array}$ & $\begin{array}{c}204 \\
6 \\
\end{array}$ & $\begin{array}{c}11 \\
0\end{array}$ & 0.57 \\
\hline Number of vessel Examined & $\begin{array}{l}1 \\
2 \\
3 \\
4 \\
5\end{array}$ & $\begin{array}{c}35 \\
9 \\
90 \\
76 \\
0\end{array}$ & $\begin{array}{l}0 \\
0 \\
4 \\
7 \\
0\end{array}$ & 0.212 \\
\hline
\end{tabular}

Table 3-2. Correlation between risk factors and the incidence of thromboembolic complications secondary to cerebral digital subtraction angiography in pretreated dual antiplatelet therapy as premedication

\begin{tabular}{|c|c|c|c|c|}
\hline Risk factor & olic complication & NO & YES & $p$-value \\
\hline Hypertension & $\begin{array}{l}\text { No } \\
\text { Yes }\end{array}$ & $\begin{array}{l}109 \\
87\end{array}$ & $\begin{array}{l}1 \\
1\end{array}$ & 0.874 \\
\hline Diabetes mellitus & $\begin{array}{l}\text { No } \\
\text { Yes }\end{array}$ & $\begin{array}{l}168 \\
28\end{array}$ & $\begin{array}{l}1 \\
1 \\
\end{array}$ & 0.155 \\
\hline Hyperlipidemia & $\begin{array}{l}\text { No } \\
\text { Yes }\end{array}$ & $\begin{array}{c}169 \\
27\end{array}$ & $\begin{array}{l}2 \\
0 \\
\end{array}$ & 0.572 \\
\hline Stroke history & $\begin{array}{l}\text { No } \\
\text { Yes }\end{array}$ & $\begin{array}{l}160 \\
29\end{array}$ & $\begin{array}{l}1 \\
1\end{array}$ & 0.167 \\
\hline heart disease & $\begin{array}{l}\text { No } \\
\text { Yes }\end{array}$ & $\begin{array}{c}188 \\
8\end{array}$ & $\begin{array}{l}2 \\
0\end{array}$ & 0.771 \\
\hline Smoking & $\begin{array}{l}\text { No } \\
\text { Yes }\end{array}$ & $\begin{array}{c}181 \\
15 \\
\end{array}$ & $\begin{array}{l}2 \\
0\end{array}$ & 0.684 \\
\hline Kidney disease & $\begin{array}{l}\text { No } \\
\text { Yes }\end{array}$ & $\begin{array}{c}194 \\
1 \\
\end{array}$ & $\begin{array}{l}2 \\
0 \\
\end{array}$ & 0.919 \\
\hline Number of vessel Examined & $\begin{array}{l}1 \\
2 \\
3 \\
4 \\
5 \\
\end{array}$ & $\begin{array}{c}4 \\
8 \\
116 \\
66 \\
1\end{array}$ & $\begin{array}{l}0 \\
0 \\
1 \\
1 \\
0 \\
\end{array}$ & 0.989 \\
\hline Type of catheter & $\begin{array}{l}\text { Taper } \\
\text { Imager } \\
\text { Simmon }\end{array}$ & $\begin{array}{c}159 \\
9 \\
28\end{array}$ & $\begin{array}{l}1 \\
0 \\
1\end{array}$ & 0.358 \\
\hline
\end{tabular}


ing Fisher's exact test, chi-square test and independent $\mathrm{t}$ tests (signigicant level 0.05). Statistical analysis was performed using the SPSS software, version 19 (IBM SPSS Statistics, IBM Corp., Armonk, NY). A p-value $<0.05$ was considered statistically significant.

\section{RESULTS}

We analyzed the complication ratio based on risk factors including hypertension, diabetes mellitus, hyperlipidemia, history of stroke, smoking, heart disease such as heart failure or arrhythmia, chronic kidney disease, and others that can affect the vascular status. Our analysis showed that these risk factors did not significantly affect the incidence of DSA-induced TEC (Table 3-1, 3-2).

There was a significant difference in the incidence of TEC between patients who took dual antiplatelet therapy and those who did not, which is consistent with our hypothesis. Of the 221 patients who did not receive antiplatelet therapy, 210 patients $(95.0 \%) \mathrm{did}$ not report neurological symptoms; however, 11 patients (5.0\%) reported various neurological symptoms including motor weakness and showed MRI-proven ischemic stroke (Fig. 1), which represents a TEC. Of the 198 patients who received dual antiplatelet therapy, $196(99.0 \%)$ showed no evidence of TEC. However, 2 $(1.0 \%)$ developed diplopia (Fig. 2) and motor weakness respectively, and acute ischemic stroke was confirmed on MRI ( $p=0.019)$ (Table 4). Of the 13 patients diagnosed with DSA-induced TEC, 7 presented motor weakness, 4 reported visual disturbance, and 1 reported dysarthria and paresis (Table 5).

\section{DISCUSSION}

Cerebral DSA and noninvasive cerebrovascular imaging modalities have shown steady improvement over the past several decades. Presently, diagnostic cerebral DSA is commonly performed for treatment planning of endovascular or open surgical proce-

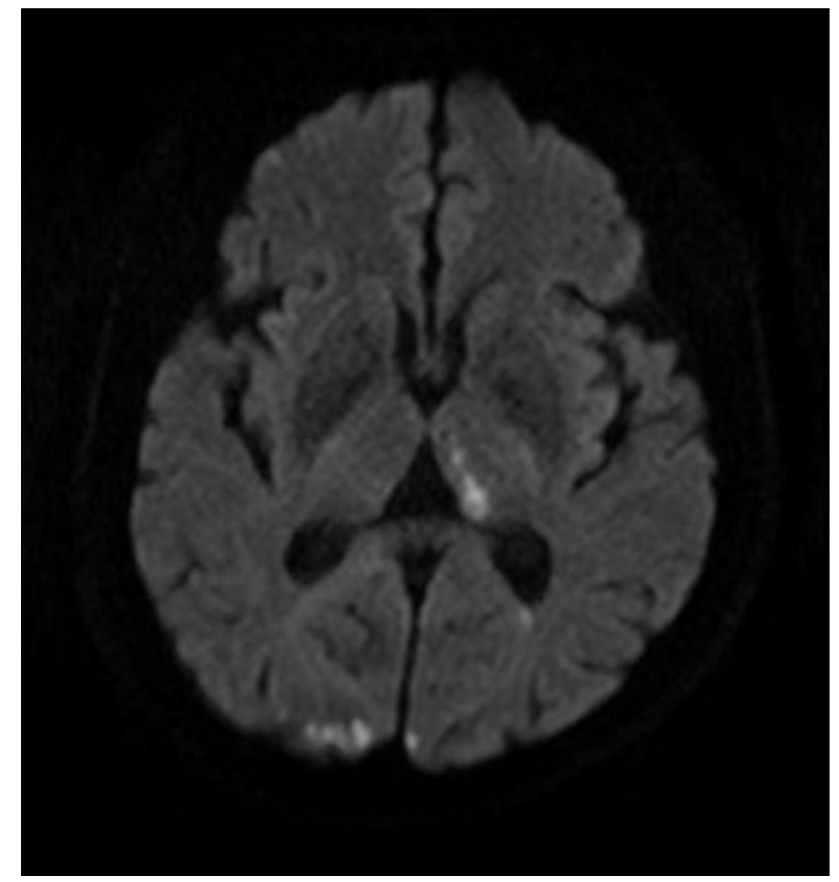

Fig. 1. Magnetic resonance image in untreated premedication Diffusion-weighted magnetic resonance imaging scan obtained in a woman who developed right-sided motor weakness immediately after diagnostic cerebral digital subtraction angiography for an unruptured aneurysm. An acute ischemic stroke involving the left thalamus and both occipital lobes was confirmed as a thromboembolic complication. Of note, she had not been administered premedication.

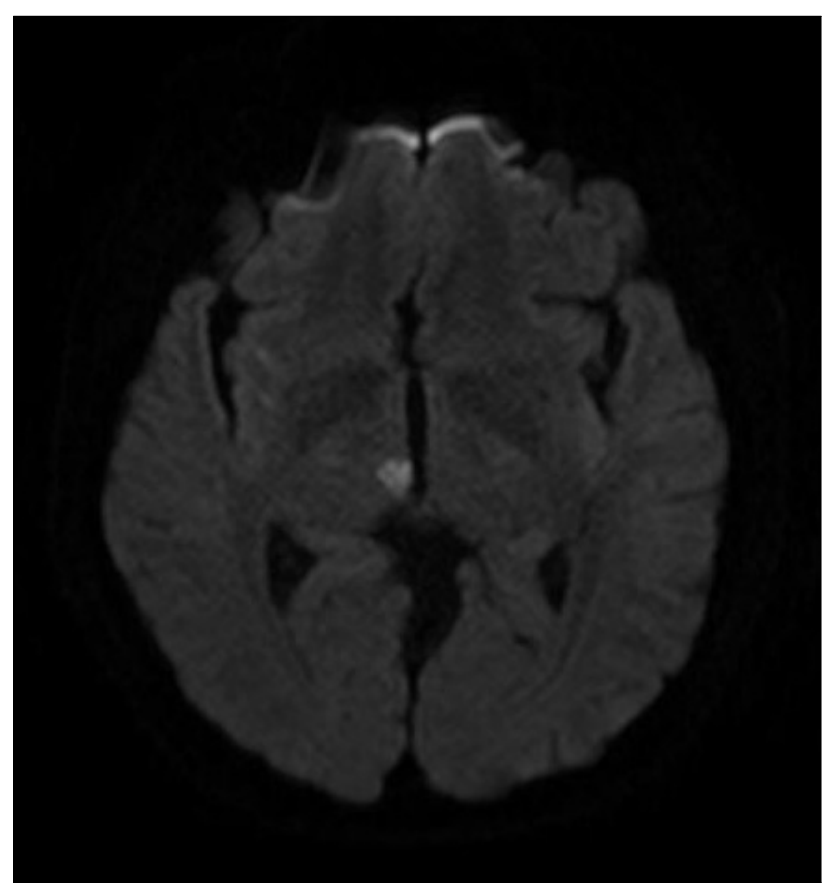

Fig. 2. Magnetic resonance image in treated premedication Image shows a man who was premedicated with dual antiplatelet therapy and was diagnosed with an acute ischemic stroke involving the right pretectal region. He complained of a diplopia. 
Table 4. Correlation between the administration of premedication and the development of thromboembolic complications

\begin{tabular}{l|crrrr}
\hline $\begin{array}{r}\text { Thromboembolic } \\
\text { complication }\end{array}$ & No & Yes & Total & p-value \\
Premedication & & & & & \\
\hline No & $210(95.0 \%)$ & 11 & $(5.0 \%)$ & 221 & \\
Yes (aspirin+cilostazol) & $196(99.0 \%)$ & $2(1.0 \%)$ & 198 & 0.019 \\
Total & $406(96.9 \%)$ & $13(3.1 \%)$ & 419 & \\
\hline
\end{tabular}

Table 5. Patients diagnosed with thromboembolic complications

\begin{tabular}{l|cl}
\hline $\begin{array}{l}\text { Symptoms as } \\
\text { thromboembolic } \\
\text { complication }\end{array}$ & No & Yes \\
\hline Motor weakness & $6(46.2 \%)$ & $1(7.7 \%)$ \\
Ocular symptom & $3(23.0 \%)$ & $1(7.7 \%)$ \\
Dysarthria & $1(7.7 \%)$ & $0(0.0 \%)$ \\
Paresis & $11(7.7 \%)$ & $0(0.0 \%)$ \\
Total & $11(84.6 \%)$ & $2(15.4 \%)$ \\
\hline
\end{tabular}

dures $^{8)}$. However, diagnostic cerebral DSA is associated with a risk of complications including TEC. To qualify as a generalized diagnostic test, cerebral DSA should be safe with a low risk of complications ${ }^{68)}$.

Diagnostic cerebral DSA may result in local complications such as access-site hematoma formation and systemic complications including headache, nausea, vomiting, and/or transient hypotension, nephropathy, and neurological deficits ${ }^{23)}$. Among the various complications of diagnostic cerebral DSA, we focused on TEC, which can cause neurological deficits.

Thromboembolism is the most common cause of ischemic stroke, which can cause transient or permanent neurological deficit including hemiparesis, aphasia, visual symptoms, and a diminished level of consciousness, among others ${ }^{2}$. Thus, thromboembolism counts as a significant complication of diagnostic cerebral DSA. Complication rates are approximately $0.55-3.2 \%$, although these vary across studies ${ }^{6 / 8}$. Most TEC occur within the first 48 hours post intervention. We defined cerebral DSA-induced TEC as the occurrence of acute ischemic stroke that was confirmed on MRI within 48 hours of testing in patients with neurological symptoms.

Presently, the key concern is to minimize diagnostic cerebral DSA-related complications and identify strat- egies to effectively manage those that have already occurred.

The risk factors for ischemic stroke after cerebral DSA include hypertension, diabetes mellitus, dyslipidemia, cardiac disorders like heart failure or arrhythmia, a history of smoking, chronic kidney disease, the number of catheters used, types of catheters

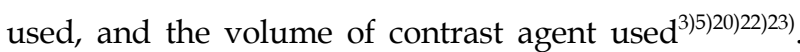
We analyzed the effect of each risk factor on the incidence of cerebral DSA-induced complications. The association between the incidence of TEC and each risk factor was non-significant.

An ischemic stroke may occur during the cerebral DSA procedure secondary to vascular spasm or neurovascular dissection following severe vascular stenosis or occlusion. However, most instances of ischemic stroke following cerebral DSA may be associated with distal embolization of air or particulate matter ${ }^{11)}$ secondary to disruption of a calcified plaque, which actually precipitates the clinical event. Air embolism can occur during catheter flushing, guidewire exchange, or contrast medium injection ${ }^{18)}$, which are related to the operator's skill. Thrombus formation may occur in catheters, in pre-existing friable intravascular thrombotic plaques, or device-induced microdissections ${ }^{17}$. In this study, a single neurosurgeon performed all cerebral DSA procedures, thereby minimizing the complication rate related to variations in operator's skill. However, TEC secondary to emboli originating from an existing thrombus when the device passes into the vessel cannot be avoided. We concluded that this pathomechanism of thrombus formation is a major contributor to cerebral DSA-induced ischemic stroke. Therefore, we assumed that preprocedural antiplatelet therapy could effectively reduce cerebral DSA-induced TEC. Moreover, we hypothesized that premedication using dual antiplatelet therapy could be more effective than the use of a single antiplatelet agent.

Several studies have reported that the dual antiplatelet therapy compared to single antiplatelet ther- 
apy could significantly lower numerical or clinical findings associated with platelet aggregation that cause thrombus ${ }^{17) 25(27) 28) 29)}$. Platelet aggregation, an important step in the process of thrombus formation, occurs through a chain of mechanisms. Antiplatelet agents are classified according to which mechanisms are inhibited. It can be divided into cyclooxygenase inhibitor, phosphodiesterase inhibitor, Adenosine disphosphonate receptor antagonist, glycopeptide IIb / IIIa antagonist and serotonin receptor antagonist ${ }^{30)}$. Simultaneous use of antiplatelet agents with these different mechanisms have shown the synergic effect ${ }^{26) 28)}$.

Aspirin, an irreversible inhibitor of cyclooxygenase, inhibits the conversion of arachidonic acid to thromboxane A2 and prevents vasospasm and platelet aggregation $^{47710)}$. The effect of aspirin lasts approximately 7 to 10 days corresponding to the lifespan of platelet $^{7)}$. The premedication period was determined for 7 days in this study based on this fact.

Cilostazol inhibits phosphodiesterase 3, which is strongly expressed in platelets and vascular smooth muscle cells ${ }^{9}$. Thus, cilostazol inhibits platelet aggregation and vascular smooth muscle proliferation and causes vascular dilatation ${ }^{13) 18) 19) 21)}$. Furthermore, several reports have demonstrated the synergistic effect of cilostazol and endogenous mediators to lower the risk of hemorrhage compared with the use of clopidogrel and endogenous mediators ${ }^{9)}$. Therefore, we preferred cilostazol over clopidogrel as premedication to lower the risk of TEC. Patients who were pretreated with dual antiplatelet therapy did not report hemorrhagic related complications.

This study suggests that preprocedural dual antiplatelet therapy can significantly reduce the cerebral DSA-induced TEC rate. However, there are some limitations on this study. First, considering the effect of learning curve of operator is the limitation of this paper, further reevaluation will be needed in the future. Second, although our population is the perfect representation of our center, we could not determine whether this population was representative of the en- tirety of population who were performed cerebral DSA. Third, this study was retrospective and consisted only of the available data at a single institution. A better designed randomized controlled trial would be needed.

\section{CONCLUSIONS}

The use of dual antiplatelet agents (aspirin and cilostazol) over a week before the procedure may reduce the risks of cerebral DSA-induced complications.

\section{ACKNOWLEDGEMENTS}

This work was supported by a grant from the Chunma medical research foundation, Korea, 2019.

\section{REFERENCES}

1. Bendszus $M$, Koltzenburg $M$, Bartsch AJ, Goldbrunner R, Günthner-Lengsfeld T, Weilbach FX, et al. Heparin and air filters reduce embolic events caused by intra-arterial cerebral angiography: a prospective, randomized trial. Circulation. 2004;110(15):2210-5.

2. Bendszus M, Koltzenburg M, Burger R, Warmuth-Metz M, Hofmann E, Solymosi L. Silent embolism in diagnostic cerebral angiography and neurointerventional procedures: a prospective study. The Lancet. 1999;354(9190): 1594-7.

3. Britt PM, Heiserman JE, Snider RM, Shill HA, Bird C, Wallace RC. Incidence of postangiographic abnormalities revealed by diffusion-weighted MR imaging. American Journal of Neuroradiology. 2000;21(1):55-9.

4. Catella-Lawson F, Reilly MP, Kapoor SC, Cucchiara AJ, DeMarco S, Tournier B, et al. Cyclooxygenase inhibitors and the antiplatelet effects of aspirin. New England Journal of Medicine. 2001;345(25):1809-17.

5. Choudhri O, Schoen M, Mantha A, Feroze A, Ali R, Lawton MT, et al. Increased risk for complications following diagnostic cerebral angiography in older patients: Trends from the Nationwide Inpatient Sample (1999-2009). Journal of clinical neuroscience : official journal of the Neurosurgical Society of Australasia. 2016 Oct;32:109-14.

6. Dion JE, Gates PC, Fox AJ, Barnett HJ, Blom RJ. Clinical events following neuroangiography: a prospective study. Stroke. 1987;18(6):997-1004.

7. Fiehler J, Ries T. Prevention and treatment of thromboembolism during endovascular aneurysm therapy. Clinical Neuroradiology. 2009;19(1):73-81. 
8. Fifi JT, Meyers PM, Lavine SD, Cox V, Silverberg L, Mangla S, et al. Complications of modern diagnostic cerebral angiography in an academic medical center. Journal of vascular and interventional radiology : JVIR. 2009 Apr;20(4):442-7.

9. Goto S. Cilostazol: potential mechanism of action for antithrombotic effects accompanied by a low rate of bleeding. Atherosclerosis Supplements. 2005 Dec 15;6(4): 3-11.

10. Gotoh F, Tohgi H, Hirai S, Terashi A, Fukuuchi Y, Otomo E, et al. Cilostazol stroke prevention study: A placebo-controlled double-blind trial for secondary prevention of cerebral infarction. Journal of stroke and cerebrovascular diseases : the official journal of National Stroke Association. 2000 Jul-Aug;9(4):147-57.

11. Hankey GJ, Warlow CP, Sellar RJ. Cerebral angiographic risk in mild cerebrovascular disease. Stroke. 1990;21(2): 209-22.

12. Jerjes-Sanchez C. Venous and arterial thrombosis: a continuous spectrum of the same disease? : European Heart Jounal. 2005 Jan;26(1):3-4.

13. Kwon SU, Cho YJ, Koo JS, Bae HJ, Lee YS, Hong KS, et al. Cilostazol prevents the progression of the symptomatic intracranial arterial stenosis: the multicenter double-blind placebo-controlled trial of cilostazol in symptomatic intracranial arterial stenosis. Stroke. 2005 Apr;36(4): 782-6.

14. Lanterna LA, Tredici G, Dimitrov BD, Biroli F. Treatment of unruptured cerebral aneurysms by embolization with Guglielmi detachable coils: case-fatality, morbidity, and effectiveness in preventing bleeding-a systematic review of the literature. Neurosurgery. 2004;55(4): 767-78.

15. Matsushige T, Kiura Y, Sakamoto S, Okazaki T, Shinagawa K, Ichinose $\mathrm{N}$, et al. Multiple antiplatelet therapy contributes to the reversible high signal spots on diffusion-weighted imaging in elective coiling of unruptured cerebral aneurysm. Neuroradiology. 2013 Mar;55(4):449-57.

16. Nishikawa $\mathrm{Y}$, Satow $\mathrm{T}$, Takagi $\mathrm{T}$, Murao $\mathrm{K}$, Miyamoto S, Iihara K. Efficacy and safety of single versus dual antiplatelet therapy for coiling of unruptured aneurysms. Journal of stroke and cerebrovascular diseases : the official journal of National Stroke Association. 2013 Jul;22(5):650-5.

17. Rahme RJ, Zammar SG, El Ahmadieh TY, El Tecle NE, Ansari SA, Bendok BR. The role of antiplatelet therapy in aneurysm coiling. Neurological research. 2014 Apr;36(4):383-8.

18. Shinohara $Y$, Katayama $Y$, Uchiyama S, Yamaguchi T, Handa S, Matsuoka K, et al. Cilostazol for prevention of secondary stroke (CSPS 2): an aspirin-controlled, double-blind, randomised non-inferiority trial. The Lancet Neurology. 2010;9(10):959-68.

19. Sudo T, Tachibana K, Toga K, Tochizawa S, Inoue $Y$, Kimura $Y$, et al. Potent effects of novel anti-platelet aggregatory cilostamide analogues on recombinant cyclic nucleotide phosphodiesterase isozyme activity. Biochemical pharmacology. 2000;59(4):347-56.

20. Tanaka H, Ueda Y, Hayashi M, Date C, Baba T, Yamashita $\mathrm{H}$, et al. Risk factors for cerebral hemorrhage and cerebral infarction in a Japanese rural community. Stroke. 1982;13(1):62-73.

21. Tanaka T, Ishikawa T, Hagiwara M, Onoda $\mathrm{K}$, Itoh $\mathrm{H}$, Hidaka H. Effects of cilostazol, a selective cAMP phosphodiesterase inhibitor on the contraction of vascular smooth muscle. Pharmacology. 1988;36(5):313-20.

22. Tanizaki Y, Kiyohara Y, Kato I, Iwamoto H, Nakayama $\mathrm{K}$, Shinohara $\mathrm{N}$, et al. Incidence and risk factors for subtypes of cerebral infarction in a general population: the Hisayama study. Stroke. 2000;31(11):2616-22.

23. Timothy J. Kaufmann M, John Huston III M, Jay N. Mandrekar P, Cathy D. Schleck B, Kent R. Thielen M, David F. Kallmes M. Complications of Diagnostic Cerebral Angiography: Evaluation of 19826 Consecutive Patients1. Radiology.n 2007;243(3):812-819

24. Yamada NK, Cross DT, 3rd, Pilgram TK, Moran CJ, Derdeyn CP, Dacey RG, Jr. Effect of antiplatelet therapy on thromboembolic complications of elective coil embolization of cerebral aneurysms. AJNR American journal of neuroradiology. 2007 Oct;28(9):1778-82.

25. Tepe G, Bantleon R, Brechtel K, Schmehl J, Zeller T, Claussen $C D$, et al. Management of peripheral arterial interventions with mono or dual antiplatelet therapythe MIRROR study: a randomised and double-blinded clinical trial. European radiology. 2012;22(9):1998-2006.

26. Geeganage CM, Diener H-C, Algra A, Chen C, Topol EJ, Dengler R, et al. Dual or mono antiplatelet therapy for patients with acute ischemic stroke or transient ischemic attack: systematic review and meta-analysis of randomized controlled trials. Stroke. 2012;43(4):1058-66.

27. Wong KSL, Chen C, Fu J, Chang HM, Suwanwela NC, Huang $\mathrm{YN}$, et al. Clopidogrel plus aspirin versus aspirin alone for reducing embolisation in patients with acute symptomatic cerebral or carotid artery stenosis (CLAIR study): a randomised, open-label, blinded-endpoint trial. The Lancet Neurology. 2010;9(5):489-97.

28. Nishikawa Y, Satow T, Takagi T, Murao K, Miyamoto S, Iihara K. Efficacy and safety of single versus dual antiplatelet therapy for coiling of unruptured aneurysms. Journal of stroke and cerebrovascular diseases : the official journal of National Stroke Association. 2013 Jul;22(5):650-5.

29. Cassar K, Ford I, Greaves M, Bachoo P, Brittenden J. Randomized clinical trial of the antiplatelet effects of aspirin-clopidogrel combination versus aspirin alone after lower limb angioplasty. British Journal of Surgery: Incorporating European Journal of Surgery and Swiss Surgery. 2005;92(2):159-65.

30. Jennings LK. Mechanisms of platelet activation: need for new strategies to protect against platelet-mediated atherothrombosis. Thrombosis and haemostasis. 2009;102(08): 248-57. 